\title{
Ph. Walter, Dictionnaire de Mythologie arthurienne
}

\section{G. Matteo Roccati}

\section{(2) OpenEdition}

\section{Journals}

\section{Édition électronique}

URL : http://journals.openedition.org/studifrancesi/10498

DOI : 10.4000/studifrancesi. 10498

ISSN : 2427-5856

\section{Éditeur}

Rosenberg \& Sellier

\section{Édition imprimée}

Date de publication : 1 décembre 2017

Pagination : 524

ISSN : 0039-2944

\section{Référence électronique}

G. Matteo Roccati, «Ph. Walter, Dictionnaire de Mythologie arthurienne », Studi Francesi [En ligne], 183 (LXI | III) | 2017, mis en ligne le 01 février 2018, consulté le 22 janvier 2021. URL : http://

journals.openedition.org/studifrancesi/10498; DOI : https://doi.org/10.4000/studifrancesi.10498

Ce document a été généré automatiquement le 22 janvier 2021.

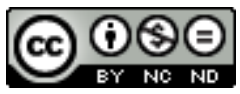

Studi Francesi è distribuita con Licenza Creative Commons Attribuzione - Non commerciale - Non opere derivate 4.0 Internazionale. 
Ph. Walter, Dictionnaire de Mythologie arthurienne

G. Matteo Roccati 


\section{RÉFÉRENCE}

PHILIPPE WALTER, Dictionnaire de Mythologie arthurienne, Paris, Editions Imago, 2014, 444

pp.

1 L'Introduction: Lire la littérature arthurienne (pp. 7-24) précise la démarche, pluridisciplinaire, fondamentalement anthropologique et comparatiste, qui a présidé à la rédaction du dictionnaire: le point de vue «est celui de la mythologie et de l'imaginaire» (p.8), «son objectif principal est le recentrage de la matière arthurienne sur les «faits» celtiques (langue, civilisation, archéologie, littérature en particulier)» (p. 11). La «littérature arthurienne», englobant ici tout texte où apparaissent des «motifs narratifs (...) récurrents dans les romans arthuriens classiques» (p. 16), est appréhendée à partir de la mythologie qui la fonde: «c'est ce socle d'images narratives où s'enracinent des noms propres que vise à cerner le présent dictionnaire» (p. 14). L'ouvrage «se veut une introduction synthétique à la mythologie arthurienne sous la forme d'un dictionnaire incluant des noms propres (de personnes, de lieux, etc.), mais aussi des thèmes et des notions clés» (ibidem). «Le but de chaque notice est de retrouver l'ancrage celtique de la notion visée» (p.21); pour les personnages, le critère adopté dans le choix des entrées a été celui «des «traits mythiques» pertinents. Autrement dit, on ne trouvera que des personnages manifestant des motifs mythiques (ou mythèmes) récurrents dans l'ensemble du corpus» (p.15). Enfin, «chaque notice est suivie d'une bibliographie d'orientation» (p. 22).

Le Dictionnaire (pp. 25-400), très riche, est suivi de la Chronologie (pp. 401-404), d'un Panorama général des récits arthuriens (éditions et traductions, classées par domaines: celtique, medio-latin, français, germanique, scandinave, anglais, néerlandais, ibérique, italien; pp. 405-424), de la Bibliographie (pp. 425-438) et de la Liste des notices. 